
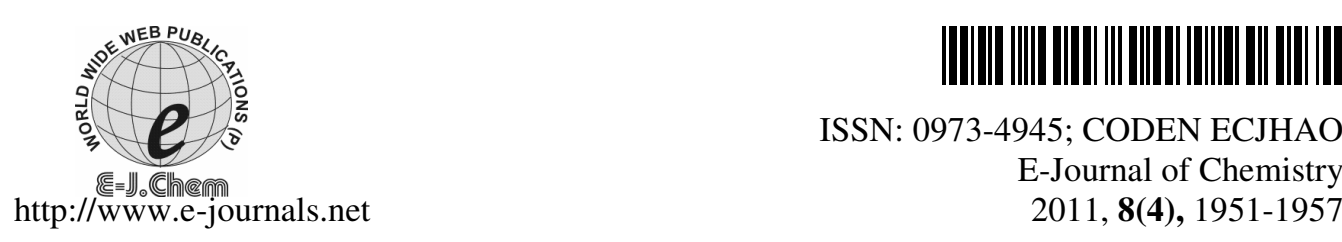

ISSN: 0973-4945; CODEN ECJHAO

E-Journal of Chemistry

2011, 8(4), 1951-1957

\title{
Bioethanol Production from Paper Fibre Residue Using Diluted Alkali Hydrolysis and the Fermentation Process
}

\author{
G.SATHYA GEETHA* and A.NAVANEETHA GOPALAKRISHNAN ${ }^{\S}$ \\ *Department of Chemistry, Velalar College of Engg and Tech \\ Erode - 638 012, Tamilnadu, India \\ ${ }^{\S}$ Centre for Environmental Studies, Anna University \\ Chennai-600 025, Tamilnadu, India \\ sweetsageeth@gmail.com
}

Received 9 December 2010; Revised 28 January 2011; Accepted 28 February 2011

\begin{abstract}
The state of art for the bioethanol production from paper fibre residue using diluted alkali hydrolysis and fermentation processes was evaluated. Hydrolysis of paper fibre residue with diluted sodium hydroxide at various time period, temperature and concentration were investigated. The paper fibre residue was pre-steamed, impregnated with diluted $\mathrm{NaOH}$ (0 to $25 \%$ ) and subsequently hydrolyzed in a reactor at temperatures that ranged between 30 to $50{ }^{\circ} \mathrm{C}$, for reaction time between 30 minutes to 150 minutes. The highest yield of monosaccharide (indicating the efficient hydrolysis of cellulose and hemi cellulose) was found at a temperature of $35^{\circ} \mathrm{C}$ for a reaction time of 90 minutes. Fermentability of hemicelluloses hydrolysate was tested using monosaccharide fermenting microorganism Penicillium chrysogenum and Saccharomyces cereviacea. The fermentability of the hydrolysate decreased strongly for hydrolysate produced at temperature higher than $50{ }^{\circ} \mathrm{C}$. The ethanol concentration of monosaccharide hydrolysate was found to be $34.06 \mathrm{~g} / \mathrm{L}$ and the ethanol yield was $0.097 \mathrm{~g} / \mathrm{g}$.
\end{abstract}

Keywords: Paper fibre residue, Diluted alkali, Fermentation, Yeast, Inhibition, 5-Hydroxy methyl furfural

\section{Introduction}

Ligno-cellulosic materials are considered to be the most promising renewable resource for fuel ethanol production. Ethanol has desirable properties as fuel, both with respect to its combustion and the possibility to use it in the low blended mixtures with gasoline ${ }^{1}$. Large-scale production of fuel ethanol today is based on sucrose from sugarcane in Brazil, or starch mainly from corn in the USA ${ }^{2}$. These processes for ethanol production are well established. The commercial production of fuel ethanol is based on simultaneous steam pretreatment and diluted alkali 
hydrolysis which is followed by enzymatic hydrolysis and fermentation. However to increase the ethanol production potential, other sources of biomass are needed. Hence, large fraction of the already established sources of biomass should be utilized. Industrial solid waste such as paper mill fibre residue would provide an abundant feedstock for ethanol production. So, the possibility of using a paper industry fibre residue as a feedstock for ethanol production was studied.

In this study, bench scale hydrolysis reactor was used for analyzing the paper fibre residue (PFR). Hydrolysis was performed for various temperatures $\left(30-50{ }^{\circ} \mathrm{C}\right)$, at varying alkali concentration (0-20\%) for varying reaction time between 30-150 minutes. The Inhibiting compound (5-Hydroxy Methyl Furfural (HMF) and furfural) concentration was also determined. Monosaccharides were analyzed after alkali hydrolysis by high performance liquid chromatography (HPLC) using a method described by theander ${ }^{3}$. The fermentability of the hydrolysate obtained was evaluated using Penicillium chrysogenum and Saccharomyces cereveacea. From the monosaccharide analysis, it is possible to determine the condition at which the yield of monosaccharide is maximum for the PFR fibre.

\section{Experimental}

Paper fibre residue (PFR) was collected from the paper industries in Erode district. PFR samples were milled and washed with water. The PFR was analyzed for its composition such as monosaccharides, lignin, moisture and fibre residues. The composition of PFR is presented in Table 1. The fibre content was determined to be $4.3 \pm 0.4 \mathrm{mg} / \mathrm{g}$ of the dry weight and the lignin content was determined to be $74.2 \pm 2.3 \mathrm{mg} / \mathrm{g}$ of the dry weight.

Table 1. Potential monosaccharide composition of paper fibre residues (PFR)

\begin{tabular}{ccc}
\hline S. No. & Monosaccharide, $\mathrm{mg} / \mathrm{g}$ & PFR composition, $\mathrm{mg} / \mathrm{g}^{*}$ \\
\hline 1 & Glucan & $45.5 \pm 2.3$ \\
2 & Mannan & $3.0 \pm 0.03$ \\
3 & Xylan & $15 \pm 1.4$ \\
4 & Galactan & $2.5 \pm 0.3$ \\
5 & Arabinan & $1.5 \pm 0.2$ \\
6 & Lignin & $74.2 \pm 2.3$ \\
7 & Acetate & $3 \pm 0.2$ \\
8 & Fibre & $4.3 \pm 0.4$ \\
\hline
\end{tabular}

*Based on dry extracted sample. Monosaccharides are reported as anhydrous monosaccharide

\section{Diluted alkali hydrolysis of the paper fibre residue (PFR)}

PFR from paper mill was processed using hammer mill, milled into $2 \mathrm{~cm}$ pieces. The PFR pieces were pre-steamed with low pressure steam of $10^{5} \mathrm{~Pa}$ for 20 minutes in a vessel, to make sure that the pores of the fibre was free from air, which may have an adverse effect on the alkali impregnated step. The pre-steamed material was stored in a cool room overnight.

The pre-steamed PFR was alkali hydrolyzed with steam explosion in 2.5 litre reactor. The PFR materials were impregnated with various concentration of sodium hydroxide solution $(0$, $5,10,15$ and $20 \%$ ) at temperatures of $30,35,40,45$ and $50{ }^{\circ} \mathrm{C}$, for $30,60,90,120$ and 150 minutes of reaction time respectively. Duplicate hydrolysis experiments were performed for reliability. The ratio of liquid/dry solid was $20 \mathrm{~mL} / \mathrm{g}$. The residues of alkali hydrolysis were then treated with concentrated phosphoric acid until the neutral $\mathrm{pH}$ was obtained ${ }^{4}$. 
In order to calculate the total monosaccharide yield from the pretreatment, the liquid phase was separated from the solid phase by filtration using a buchner funnel and its volume was determined. The solid fraction was then washed with pure water and washing water was collected for further analysis. The amount of washed water accounts for 3 to 4 times larger than the amount of liquid separated after hydrolysis. Monosaccharide concentration was analysed by HPLC according to national renewable energy laboratory (NERL) procedures for the determination of the structural carbohydrate and lignin biomass $\mathrm{s}^{5,6}$.

Generally, during chemical hydrolysis, the inhibiting compounds inhibit the monosaccharide formation. The inhibiting compounds namely, 5-HMF and furfural concentration is meagre resulting in negligible monosaccharide degradation.

The washed samples were kept in the refrigerator for further enzymatic treatment. Thus pretreated PFR samples were stored at $4{ }^{\circ} \mathrm{C}$ in refrigerator until they were used for the enzymatic hydrolysis for the ethanol production.

\section{Enzymatic hydrolysis and fermentation}

Fungal strains isolated from the waste grapes were used for enzymatic hydrolysis. Waste grapes collected from the market was mashed and filtered. The filtrate, pomace was fermented in anaerobic condition. Penicillium chrysogenum, the dominant fungal species was isolated from pomace ${ }^{7}$. Similarly, Saccharomyces cereviacea, the common yeast was also isolated from the pomace and sub-cultured in the laboratory.

These cultures were purified, cultured, sub-cultured and maintained in laboratory conditions. The cells of Penicillium chrysogenum and Saccharomyces cereviacea (yeast) were maintained in agar plates made from yeast extract $10 \mathrm{~g} / \mathrm{L}$, peptone from soy $20 \mathrm{~g} / \mathrm{L}$, agar $20 \mathrm{~g} / \mathrm{L}$ and glucose $20 \mathrm{~g} / \mathrm{L}$ as an additional carbon source. Inoculum was prepared aerobically in $1000 \mathrm{~mL}$ baffled conical flasks in a rotary shaker at $120 \mathrm{RPM}$ at $30{ }^{\circ} \mathrm{C}$ for $24-36 \mathrm{~h}$. The growth medium was a defined medium ${ }^{8,9}$. Cells were harvested by centrifugation and washed with $1 \% \mathrm{NaCl}$. These were again centrifuged and washed with distilled water and dried for $24 \mathrm{~h}$. Cell dry weight was determined from duplicate samples.

Fermentation was carried out in $50 \mathrm{~mL}$ conical flask with $35 \mathrm{~mL}$ of medium, placed in a shaker bath at $120 \mathrm{RPM}$ at $30{ }^{\circ} \mathrm{C}$. The composition of fermentation medium per litre are $\left(\mathrm{NH}_{4}\right)_{2} \mathrm{SO}_{4}(0.47 \mathrm{~g}), \mathrm{KH}_{2} \mathrm{PO}_{4}(12.8 \mathrm{~g}), \mathrm{Na}_{2} \mathrm{HPO}_{4}(0.51 \mathrm{~g}), \mathrm{MgSO}_{4} .7 \mathrm{H}_{2} \mathrm{O}(0.47 \mathrm{~g})$, yeast extract $(0.94 \mathrm{~g})$ and hydrolysate $(874 \mathrm{~mL})$. The hydrolysate was $\mathrm{pH}$ adjusted to 5.5 with $2 \mathrm{M} \mathrm{NaOH}$. Each flask was equipped with a cotton stopper through which, a syringe for sample withdrawal was inserted. Both Penicillium chrysogenum and Saccharomyces cereviacea inoculums were added at an initial cell concentration of 40 FPU and $10 \%$ respectively ${ }^{10,11}$. Sampling was conducted until 120 hours and the metabolites samples were centrifuged immediately and stored at $-18{ }^{\circ} \mathrm{C}$ for later analysis.

Analysis

Samples were centrifuged and filtered through $0.2 \mu \mathrm{m}$ filters. The concentration of monosaccharide namely; xylose, galactose, mannose and arabinose were determined using (Aminex HPX-87 P, Bio-Rad) at $85{ }^{\circ} \mathrm{C}$. The concentration of ethanol, furfural and 5-HMF were determined on an Aminex HPX-87 H column at $65{ }^{\circ} \mathrm{C}$. All the compounds were detected with refractive index (RI) detectors.

\section{Results and Discussion}

The optimal condition for hydrolysis of the lignocellulose and hemi-cellulose part of the present substrate is equivalent to a maximum yield of monosaccharide. The obtained monosaccharide yield is shown in Table 2 . The maximum yield of monosaccharide yield is 
obtained at $35{ }^{\circ} \mathrm{C}$ temperature for a reaction time of 90 minutes with $10 \%$ alkali concentration. The monosaccharide yield is exhibited graphically in Figure 1. The inhibitors 5-HMF was found to be comparatively low for the optimum temperature as shown in the Figure 2.

Table 2. Monosaccharide yield obtained from diluted alkali hydrolysis of paper fibre residue (PFR)

\begin{tabular}{ccc}
\hline Temperature, ${ }^{\circ} \mathrm{C}$ & Residence time, $\min$ & Yield of monosaccharide, $\mathrm{g} / \mathrm{kg}^{\mathrm{a}}$ \\
\hline 30 & 60 & $70.30 \pm 0.09$ \\
30 & 90 & $71.41 \pm 0.20$ \\
30 & 120 & $65.38 \pm 0.23$ \\
35 & 60 & $72.28 \pm 0.12$ \\
35 & 90 & $77.39 \pm 0.23$ \\
35 & 120 & $70.59 \pm 1.17$ \\
40 & 60 & $68.27 \pm 0.05$ \\
40 & 90 & $66.56 \pm 0.16$ \\
40 & 120 & $59.78 \pm 0.37$ \\
45 & 60 & $63.31 \pm 0.26$ \\
45 & 90 & $55.23 \pm 0.15$ \\
45 & 120 & $50.20 \pm 0.14$ \\
\hline
\end{tabular}

The concentration of $\mathrm{NaOH}$ used was $10 \% \mathrm{w} / \mathrm{w}$ of water. The initial dry weight content was $25 \%{ }^{a}$ Based on PFR dry weight

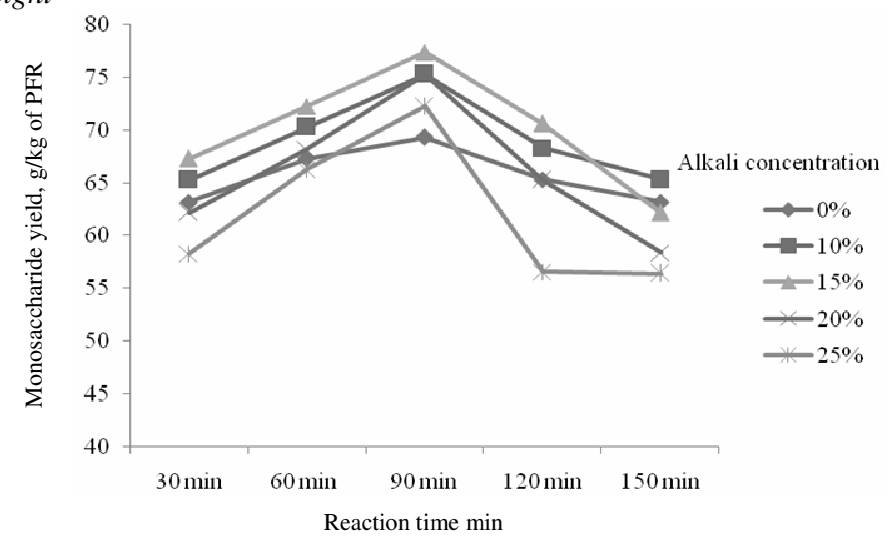

Figure 1. Monosaccharide yield after pretreatment with diluted $\mathrm{NaOH}$ hydrolysis at $35^{\circ} \mathrm{C}$

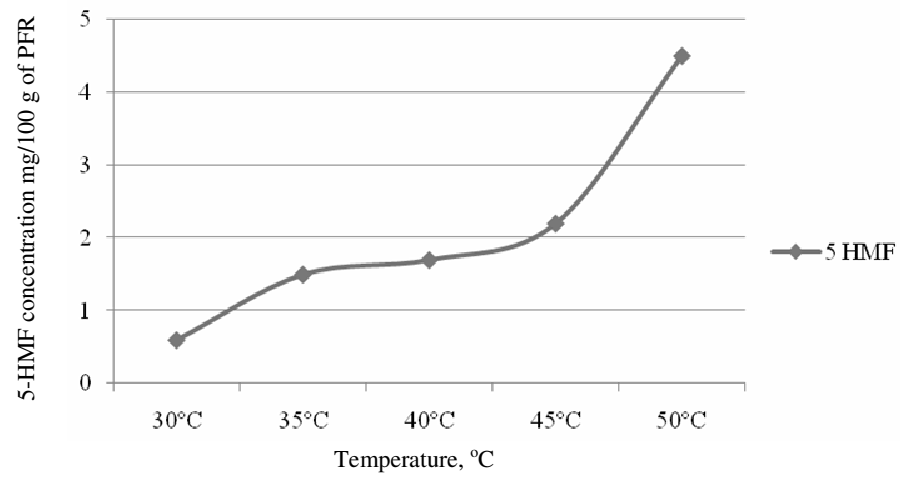

Figure 2. Yield of furfural obtained from hydrolysis of PFR at different temperatures. $10 \% \mathrm{w} / \mathrm{w}$ of $\mathrm{NaOH}$ was used and the residence time was $90 \mathrm{~min}$ 
The degradation of hemicellulose is a gradual process where long polymers are gradually degraded to oligosaccharides and finally mono-saccharides. The highest monosaccharide sugar yield obtained is $77.39 \pm 0.23 \mathrm{~g} / \mathrm{kg}$ of the hydrolyzed liquid. The yield of furfural increased with increasing temperature. Hence, at low temperature the furfural concentration is negligible resulting in high monosaccharide yield.

The representative set of hydrolysate, from the diluted alkali hydrolysis pretreatment experiment, was further hydrolysed in fermentation experiments, to assess their monosaccharide yield and its toxicity. For enzymatic hydrolysis, the natural fermenting fungal strains namely Penicillium chrysogenum and Saccharomyces cereviacea were isolated from waste grapes. Penicillium chrysogenum performs enzyme hydrolysis and its composition is represented in Table 3, whereas, Saccharomyces cereviacea performs fermentation process. The monosaccharide and ethanol concentrations after the fermentation of PFR at various time intervals were represented in Table 4.

Table 3. Composition of hydrolysate used in the fermentability test

\begin{tabular}{cccccc}
\hline $\begin{array}{c}\text { Conditions of } \\
\text { hydrolysate preparation }\end{array}$ & $\begin{array}{c}\text { Glucose, } \\
\mathrm{g} / \mathrm{L}\end{array}$ & $\begin{array}{c}\text { Xylose, } \\
\mathrm{g} / \mathrm{L}\end{array}$ & $\begin{array}{c}\text { Arabinose, } \\
\mathrm{g} / \mathrm{L}\end{array}$ & $\begin{array}{c}\text { Furfural, } \\
\mathrm{g} / \mathrm{L}\end{array}$ & $\begin{array}{c}\text { HMF, } \\
\mathrm{g} / \mathrm{L}\end{array}$ \\
\hline $30^{\circ} \mathrm{C}, 60 \mathrm{~h}$ & 78.1 & 11.1 & 0.08 & 0.08 & 0.54 \\
$35^{\circ} \mathrm{C}, 72 \mathrm{~h}$ & 80.4 & 13.1 & 0.10 & 0.20 & 0.75 \\
$37^{\circ} \mathrm{C}, 72 \mathrm{~h}$ & 83.5 & 15.2 & 0.20 & 0.28 & 0.90 \\
$40^{\circ} \mathrm{C}, 72 \mathrm{~h}$ & 81.6 & 14.3 & 0.15 & 0.25 & 0.81 \\
$45^{\circ} \mathrm{C}, 72 \mathrm{~h}$ & 77.1 & 12.3 & 0.09 & 0.21 & 0.74 \\
\hline
\end{tabular}

All hydrolysates were produced using $10 \% \mathrm{w} / \mathrm{w} \mathrm{NaOH}$. In the fermentation experiments, the hydrolysates were diluted somewhat due to addition of other medium components

Table 4. Ethanol and monosaccharide concentration at various time intervals during fermentation

\begin{tabular}{ccc}
\hline Time, $\mathrm{h}$ & $\begin{array}{c}\text { Ethanol concentration, } \\
\mathrm{g} / \mathrm{L}\end{array}$ & $\begin{array}{c}\text { Monosaccharide } \\
\text { concentration, } \mathrm{g} / \mathrm{L}\end{array}$ \\
\hline 12 & 28.68 & 83.5 \\
24 & 30.23 & 71.5 \\
36 & 31.53 & 60.5 \\
48 & 32.68 & 51.5 \\
72 & 34.06 & 40.3 \\
96 & 33.21 & 35.3 \\
120 & 31.98 & 30.2 \\
132 & 28.5 & 20.6 \\
\hline
\end{tabular}

The maximum attainable ethanol concentration $\left(\mathrm{C}_{\mathrm{EtOH}}\right)$ can be calculated as, 0.51 times the sum of glucose and xylose concentration. Adopting this method, it is found that more than $80 \%$ of $\mathrm{C}_{\mathrm{EtOH}}$ was found for the hydrolysate produced at $37{ }^{\circ} \mathrm{C}$, with an ethanol concentration around $34.06 \mathrm{~g} / \mathrm{L}$ of monosaccharide hydrolysate. Fermentation of the monosaccharide for ethanol production is graphically represented in Figure 3. Ethanol yield is found to be around $0.097 \mathrm{~g} / \mathrm{g}$ of the PFR.

In this study, the hydrolysis of paper fibre residue (PFR) was optimum at $10 \% \mathrm{NaOH}$ concentration, with a temperature of $35^{\circ} \mathrm{C}$ and a reaction time of $90 \mathrm{~min}$. At this condition, the monosaccharide yield was close to $80 \%$ of the theoretical value. 


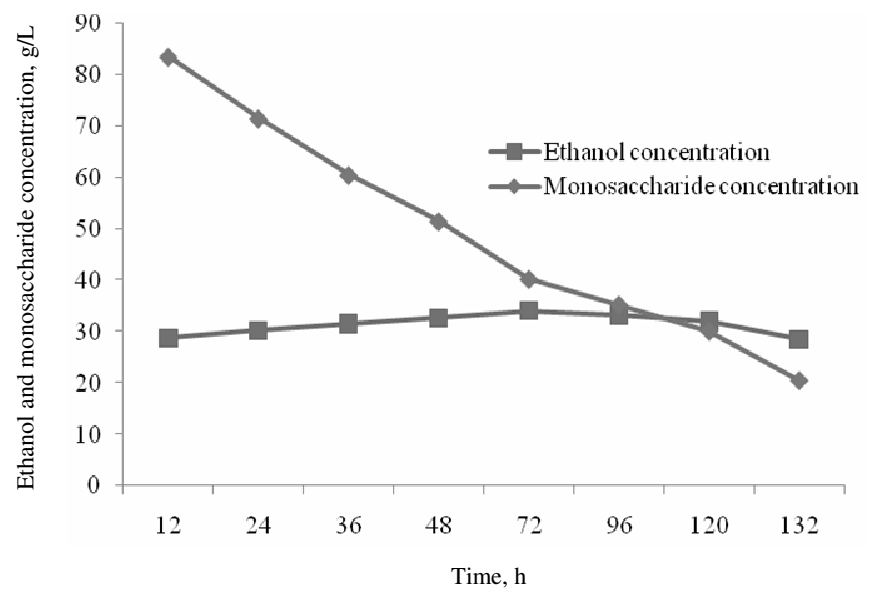

Figure 3. Fermentation of PFR hydrolysate for ethanol production at $50{ }^{\circ} \mathrm{C}$ and 72 minutes hydrolysis time

Bagasse is a straw material, which like PFR has relatively high xylan content. Literature reported a total pentason content of $0.268 \mathrm{~g} / \mathrm{g}$ in bagasse, with a ratio of arabinose to xylose of 0.11 . The maximum xylose and arabinose yields from bagasse were thus 0.274 and $0.03 \mathrm{~g} / \mathrm{g}$ respectively ${ }^{12}$. An extensive study concerning hydrolysis of the hemicellulose ${ }^{12}$, reported a maximum xylose yield of about $80 \%$, which is similar to this study.

The reason for the lower monosaccharide yield from cellulose, than from hemicellulose can be understood from the simple kinetic model proposed already ${ }^{13,14}$. Literatures ${ }^{15,16}$ reports that for xylose degradation, a lower temperature (and thus longer hydrolysis times) may be advantageous for optimizing monosaccharide yield.

A monosaccharide fermenting microorganism is needed for efficient utilization of the monosaccharides. Hence, Saccharomyces cereviacea isolated from grapes was used for fermentation, which is in acceptance with the literature ${ }^{17}$, where commercial yeast was used for fermentation.

\section{Conclusion}

The paper fibre residue (PFR) was found to be advantageous in yielding monosaccharide at optimum hydrolysis condition. The monosaccharide yield was about $80 \%$ at $35{ }^{\circ} \mathrm{C}$ for $10 \%$ alkali concentration in a reaction time of 90 minutes. The ethanol concentration of monosaccharide hydrolysate is around $34.06 \mathrm{~g} / \mathrm{L}$ and the ethanol yield of PFR was found to be around $0.097 \mathrm{~g} / \mathrm{g}$. This yield of ethanol is much more profitable comparative to the typical bioethanol production from other lignocellulosic materials which are available in the market.

\section{References}

1. Galbe M and Zacchi G, Appl Microbiol Biotechnol., 2002, 59, 618-628.

2. Wheals A E, Basso L C, Alves D M G and Amorim H V, Trends Biotechnol., 1999, 17(12), 482-487.

3. Theander O and Westerlund E A, J Agric Food Chem., 1986, 34, 330-336.

4. Zhang Y H P, Cui J, Lynd L R and Kuang L R, Biomacromolecules, 2006, 7, 644-648

5. $\quad$ Sun Y and Cheng J, Biores Technol., 2002, 83(1), 1-11.

6. Taherzadeh M J, Eklund R, Gustafsson L, Niklasson C and Liden G, Ind Eng Chem Res., 1997, 36, 4659-4665. 
7. Nigam J N, J Biotechnol., 2001, 87, 17-27.

8. Olsson L and Hahn-Heagerdal B, Proc Biochem., 1993, 28, 249-257.

9. Taherzadeh M, Gustafsson L, Niklasson C and Liden G, J Biosci Bioeng., 1999, 87(2), 169-174.

10. Taherzadeh M J, Gustafsson L, Niklasson C and Liden G, Appl Microbiol Biotechnol., 2000, 53(6), 701-708.

11. Lavarack B P, Griffin G J and Rodman D, Biomass Bioenergy, 2002 23(5), 367-380.

12. Kim S.B and Lee Y Y, Biotechnol Bioeng Symp., 1987, 17, 71-84.

13. Saeman J F, Ind Eng Chem., 1945, 37(1), 43.

14. Nilvebrant N O, Persson P, Reimann A, De Sousa F, Gorton L and Jonsson L J, Appl Biochem Biotechnol., 2003, 105, 615-628.

15. Larsson S, Palmqvist E, Hahn-Heagerdal B, Tengborg C, Stenberg K, Zacchi G and Nilvebrant N O, Enzyme Microb Technol., 1999, 24, 151-159.

16. Gong C S, Cao N J, Du J and Tsao G, Adv Biochem Eng Biotechnol., 1999, 65, 208-241. 


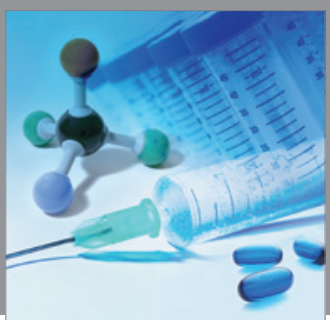

International Journal of

Medicinal Chemistry

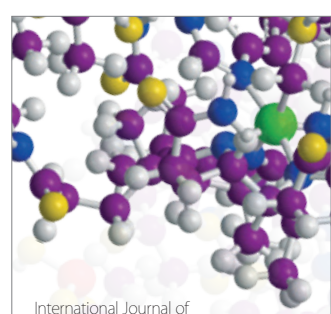

Carbohydrate Chemistry

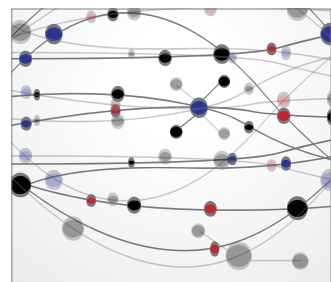

The Scientific World Journal
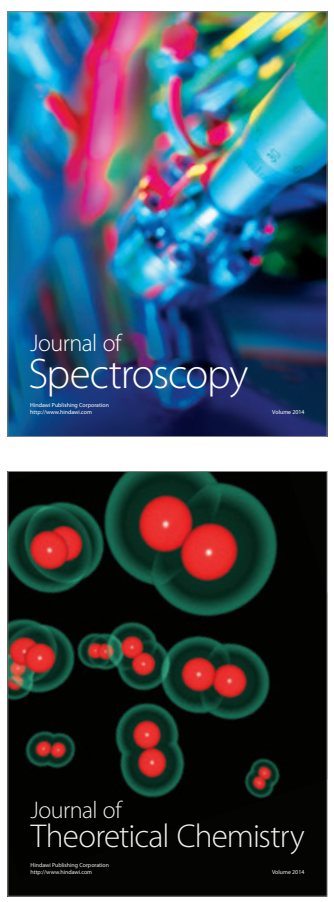
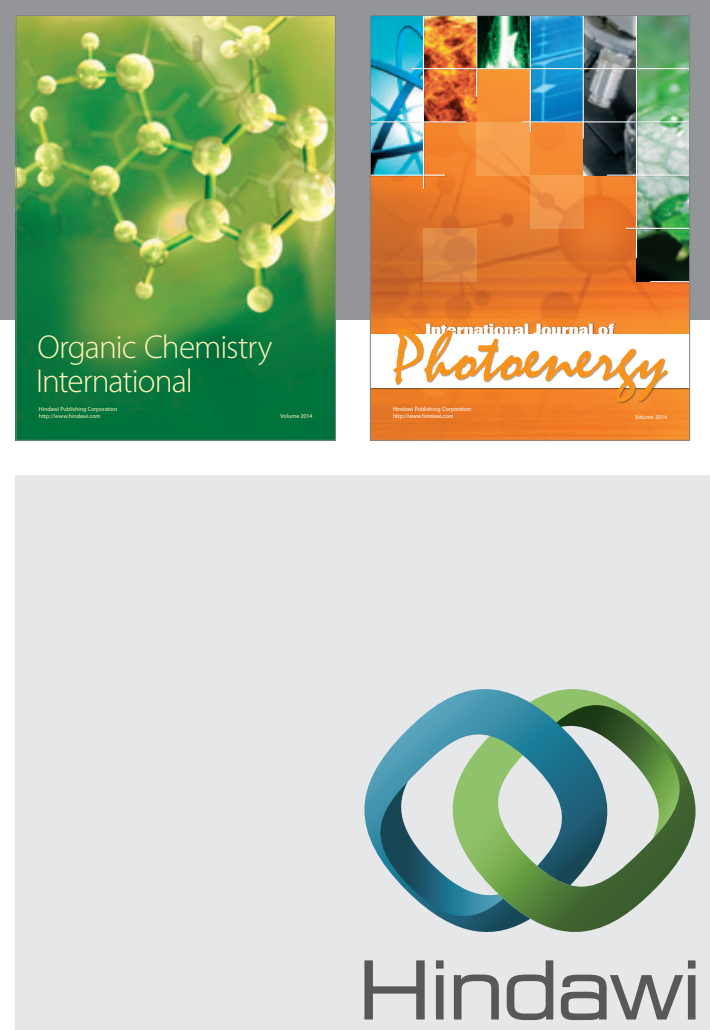

Submit your manuscripts at

http://www.hindawi.com
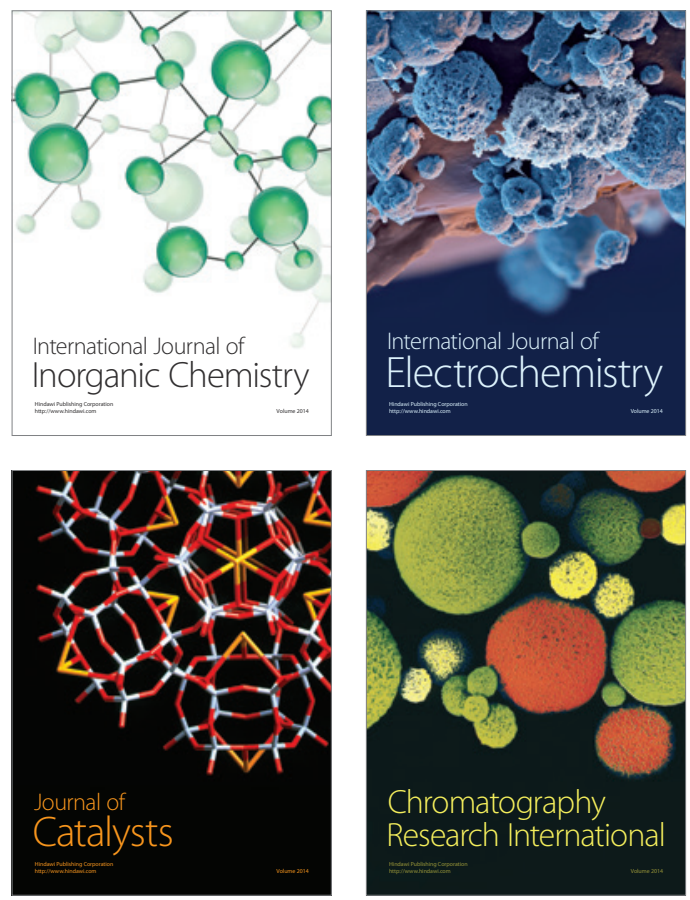
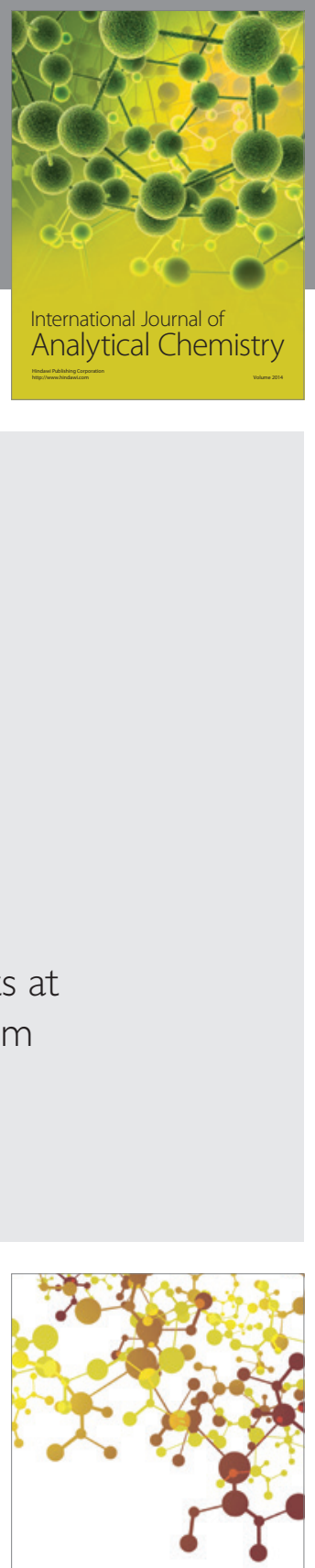

Journal of

Applied Chemistry
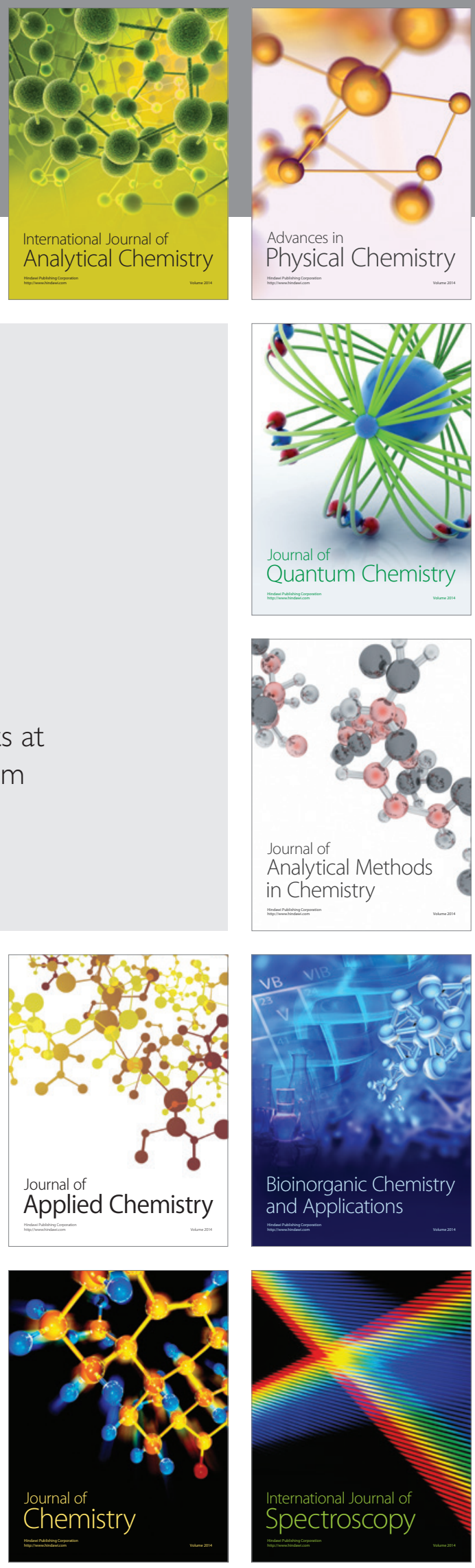